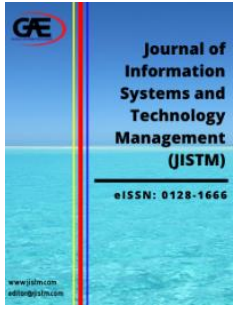

\author{
JOURNAL OF INFORMATION \\ SYSTEM AND TECHNOLOGY \\ MANAGEMENT (JISTM) \\ WWw.jistm.com
}

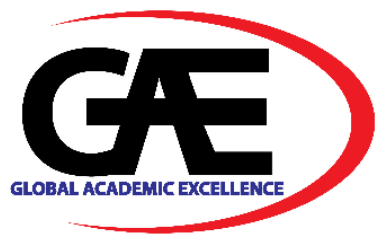

\title{
DAMAGE INSPECTION ON PIER OF SG. PERAK RESERVOIR BRIDGE USING ACCELEROMETER AND GNSS
}

\author{
Masreta Mohd $^{1 *}$, Othman Zainon², Zulkifli Majid ${ }^{3}$, Abdul Wahid Rasib ${ }^{4}$ \\ 1 Faculty of Built Environment and Surveying, Universiti Teknologi Malaysia, Malaysia \\ Email: mmasreta@yahoo.com \\ 2 Faculty of Built Environment and Surveying, Universiti Teknologi Malaysia, Malaysia \\ Email: othman@utm.my \\ 3 Faculty of Built Environment and Surveying, Universiti Teknologi Malaysia, Malaysia \\ Email: zulmajid@utm.my \\ $4 \quad$ Faculty of Built Environment and Surveying, Universiti Teknologi Malaysia, Malaysia \\ Email: wahid@utm.my \\ Corresponding Author
}

\section{Article Info:}

\section{Article history:}

Received date: 01.10.2021

Revised date: 01.11.2021

Accepted date: 20.11 .2021

Published date: 01.12.2021

\section{To cite this document:}

Mohd, M., Zainon, O., Majid, Z., \& Rasib, A. W. (2021). Review Of International GNSS Data Sharing Policy Frameworks And Practices. Journal of Information System and Technology Management, 6 (24), 265277.

DOI: $10.35631 /$ JISTM.624025

This work is licensed under $\mathrm{CC}$ BY 4.0

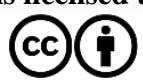

\begin{abstract}
:
Sg. Perak Reservoir Bridge where it is commonly known to be heavily utilized by heavy vehicles on daily basis. Therefore, the practices of inspection and maintenance of this bridge are essential tasks in prolonging its lifespan especially as it is utilized heavily with heavy vehicles. The act of inspecting damage that occurred at a pier is done through the use of technical equipment as an additional method invalidating visual inspection obtained through vibration reading, and validating in inspection reading analysis as additional information to confirm for any structural damages. The use of using Global Navigation Satellite System (GNSS) can be employed for continuous monitoring and the use of accelerometers, which are components of the ambient vibration method, served to be an integral part of the information obtained on the changes in the dynamic structural features detected. The vibration measurement can display natural frequencies that depended on the weight, material, pressure, and tension as well as the geometry of the object. This data obtained can therefore be used to furnish additional information on the capacity and condition of the structure. The results indicated that maximum vibration on two piers inspection are recorded at $53.7 \mathrm{~mm} / \mathrm{s} 2$ and $49.6 \mathrm{~mm} / \mathrm{s} 2$ using an Accelerometer indeed heavy vehicles traffic flow is a factor in influencing bridge vibration by traffic transport diversity between west and east lanes of both sides of the bridge.
\end{abstract}


Keywords:

Inspection, Vibration, Accelerometer, GNSS

\section{Introduction}

The factors affecting bridge service-ability are extreme loading, ageing, and increasing traffic volume. (Xi et al., 2021). The inspection and maintenance of the bridge are essential tasks in prolonging its lifespan especially as it is utilized by heavy vehicles. Therefore, the inspection on the pier is done to measure the vibration on the Sg. Perak Reservoir bridge. One main cause of bridge damage is due to vibration that is becoming a causative force where the ambient vibration contains an uncontrolled load function which is the difference from forced vibration. Moreover, it is also usually caused by unintentional man-made or atmospheric disturbances, for example, winds, floods, and passing vehicles. (Bao \& Liu, 2017).

Alternative energy sources such as vibrations on bridges can occur through vehicle traffic, wind, and even people. The ability of the vibrational effect depends on the strength as well as the frequency of the amount of energy produced. The vibration energy is usually not continuous nor continuous along the bridge (Gaglione et al., 2018).

The Sg. Perak Reservoir Bridge is an important structure in the North of Malaysia, which serve as the crucial link in the transport network between West and East Malaysia.

The inspection and maintenance of the bridge is an essential task in prolonging its lifespan, especially for bridges as they are often time being constantly plied with heavy vehicles. The invisible damages, of cause, cannot be easy being identified by visual or manual inspection alone. Therefore, bridge damage detection is performed mainly inspection, which is periodic often subjective (Fernando et al., 2020). This information was revealed by data collated on vehicle route census which was done by Public Work Department (PWD) throughout the year 2017. During the observation, wind gusts of up to $70 \mathrm{~km} / \mathrm{h}$ were experienced. Traffic loading could be very heavy, especially at rush hours in the early morning and evening when tidal traffic flows were evident. The condition of Sg. Perak Reservoir Bridge - a rather old bridge structure, can be very dangerous for pedestrians as the space on the shoulder of the bridge is not more than $1000 \mathrm{~cm}$ in width. Hence, very careful consideration is necessary during the process of data acquisition.

Statistically, there are over $40 \%$ of bridges that the bridge pole height exceeds $40 \mathrm{~m}$. Therefore, the probability of damage to the pier is higher in the flexibility of the ductility factor of its failure compared to what was determined by the ductility factor of the displacement on the pier (Chen, Zheng, Zhou, Chen, \& Li, 2020). Therefore, they can identify the presence of damage and location as well as its type in a particular structural system (Khodabandehlou, Pekcan, \& Fadali, 2019). Tests on the actual vibration data collected from the bridge had indicated that the system developed can maintain energy-neutral operation and conserve energy. This may provide some general guidelines and considerations for the development of vibration energy intake systems for bridge applications (Gaglione et. al., 2018).

In this paper, our goal is to explain the method of data acquisition and to determine the notification system as an additional feature to be added to the list of inspections by the 
inspector. This paper also describes a geotag system to detect the location of the pier in Google Maps.

The inspection measurement analysis can obtain a natural frequency that depends on the weight, material, pressure and tension as well as the geometry of the object. Therefore, this data can be used to obtain additional information on the capacity and condition of the structure together with the visually manual monitoring information. The accuracy of 3D millimetre positioning at GNSS can be maintained for continuous monitoring.

Opportunities undertaken to carry out GPS-based assessments would lead to more information about the state of key infrastructure projects, and improved knowledge of 'as-built or in-service performance. The advantages of using GPS are the relative ease of implementation achieved on structures such as long-span bridges where alternative surveying methods may be problematical (Roberts et al., 2012).

\section{Scope of work}

In this study, the researchers emphasized only 3 observation points that were done on the bridge. They were positioned on a straight line where two were placed at both ends of the bridge whereas the other was placed in the middle of the bridge. The question is why were these actions done as such? As all had known, every vehicle will enter at the entrance of the bridge and continued to leave to the last exit-point of the bridge.

These 3 observation points are important to be used to collect vibration data together with their location coordinates. The fact that the length of the Sg. Perak Reservoir Bridge is more than 800 meters therefore the observations were done the whole day that was from morning until late noontime. Every observation point is observed for several minutes that could take up until approximately 15 minutes to ensure the frequency of vehicles passing through the bridge at a fixed time.

The frequency of vehicles is based on the researchers' observations on the very first day of the study which will serve as points of reference. Based on all the frequencies of the observations that had been tabulated, the researchers had decided on the time of observation to be early in the morning, near midday and the early part of the afternoon at 3:00 pm. However, the intensely hot weather will be a critical factor for the researchers to remain longer on the bridge to carry their observations.

(TNR, 12, single spacing, justify)

\section{Description of the Study Area}

Sg. Perak Reservoir Bridge was built in 1978, as illustrated in Figure 1. It spans across the Banding Lake, between Gerik and the island of Banding, accommodating two vehicle lanes and a non-pedestrian walkway. 


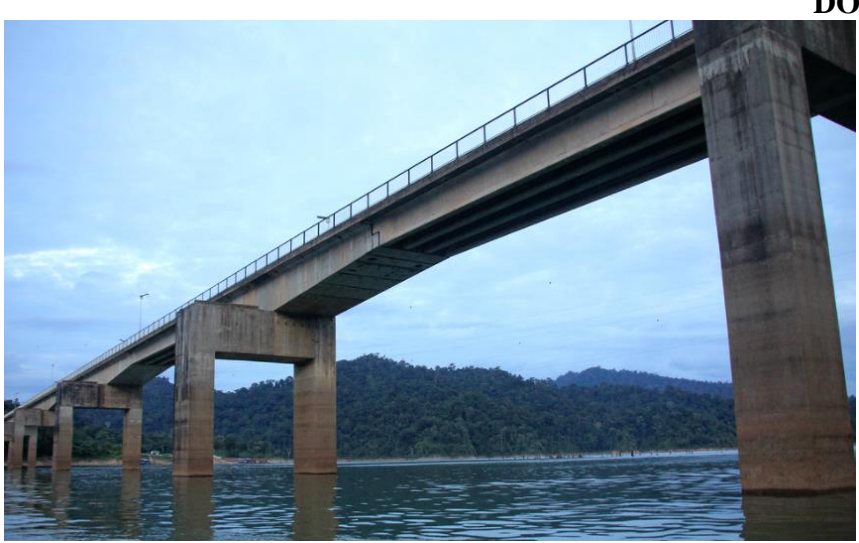

DOI: 10.35631/JISTM.624025

Figure 1: The Structure Of Sungai Perak Reservoir Bridge

It is an asymmetrical suspension bridge having a total length of 880.52 meters over fourteen spans where the maximum span is 91.46 meters, and the width of the carriageway is 8.48 meters. It has a non-Reinforced Concrete (RC) tower.

Area orientation is initially planned as the appropriate time to conduct the beginning and the ending of the whole observation process. The safety of the observer and the safety of the equipment are the important things that need to be ensured during the orientation. Once ensured that the observations can be made smoothly and effectively, the location of the monument is built in an area that can receive more than 5 satellites and met the set criteria of a minimum satellite with the face angle of 10 degrees and with the ability to track more than 5 satellites.

The scope of the study on the structure of this bridge is to look at the changes in the vibration mark as a basic technique of detection based on vibration through the dynamic characteristics of the physical structure of the bridge. (Aasim et al., 2020).

\section{Methodology}

The necessities of data acquisition were twofold. Firstly, to collect enough vibration data under real traffic conditions to be able to process them offline and power profile our hardware during simulation (Gaglione et al., 2018). Secondly, this study aims to do an on-site inspection to find the location and assess the damages to each of the bridge piers.

Through data acquisition, there were 3 station points created on this bridge and marked for further observations to collect data on the pier between the slabs that are parallel to each pier and observed simultaneously with a fast static method. The additional method in the implementation of appropriate methods for data acquisition and analysis is to detect the normal behaviour of undamaged and damaged structures.

The acquisition of all the based stations' data begun on October 10, 2019, with the orientation of the area to identify and plan logistics which were to carry out observations on the next day on the East-West Highway, Gerik Perak. The designation of three (3) base stations, Static method observations were conducted on 11 October 2019, and each base station was observed for 4 hours. The observation time started at 10.00 am and ended by 3:00 pm. 
Processing for the based stations was carried out on October 20, 2019, using Trimble Business Centre software version 3.50. Station data downloaded from sever Jabatan Ukur dan Pemetaan Malaysia (JUPEM) www.rtknet3.gov.my/SpiderWeb was used as a reference. The reference station used is the Virtual Reference Station.

Data is downloaded using Microsoft Activesync, the data is in RAW data format (T02). Processing is done by using Trimble Business Centre version 3.50, and the processing criteria are with fixed solution type and 10 maximum iterations. Data adjustments are made using the Trimble Business Centre version 3.50, the data that had been processed and reviewed are then exported to the TDEF (Trimble Data Exchange Format). A total of two TDEF files were generated during the processing exercise. Both data are collected and uploaded into the software. Adjustments are made in a full constraint that are using 3 reference stations as reference stations. These coordinates have been set and entered into the RINEX JUPEM data without the need to change the coordinates set in the RINEX. After the control station is observed and processed, the observed station data is observed with the Fast Static technique.

A two-day observation is required to complete the observation. Observations are made by GNSS during the peak hours of traffic vehicles and are also observed when the bridge is not in use (no vehicles passing through). The observation points were placed on the shoulder of the road over the bridge and centred on the pier by ensuring that the distance between each observation point is approximately 250 meters apart. After the adjustments are made, the final coordinates can be produced by the three main coordinates, namely the coordinates of GDM 2000 and Cassini Geocentric.

Table 1 shows the locations of three (3) reference stations that have been set up namely BASE 1, BASE 2, BASE 3 and VRS. This station is referred to as a Virtual Reference Station (VRS). VRS is a reference station generated through JUPEM SpiderWeb in Malaysia. This reference station is powered by MyRTK Network Malaysia station which is operated 24 hours daily. Only three (3) stations were used for this purpose of observation and complete information regarding this station can see in Figure 2 below.

Table 1: Reference Station Coordinates

\begin{tabular}{|c|c|c|c|}
\hline Station & Latitude & Longitude & Height (m) \\
\hline Base 1 & $5^{\circ} 32^{\prime} 36.78^{\prime \prime} \mathrm{N}$ & $101^{\circ} 19^{\prime} 49.09^{\prime \prime} \mathrm{E}$ & 262.125 \\
\hline Base 2 & $5^{\circ} 32^{\prime} 32.84^{\prime \prime} \mathrm{N}$ & $101^{\circ} 20^{\prime} 44.17^{\prime \prime} \mathrm{E}$ & 279.616 \\
\hline Base 3 & $5^{\circ} 33^{\prime} 05.57^{\prime \prime} \mathrm{N}$ & $101^{\circ} 20^{\prime} 51.84^{\prime \prime} \mathrm{E}$ & 238.836 \\
\hline VRS & $5^{\circ} 33^{\prime} 06.26^{\prime \prime} \mathrm{N}$ & $101^{\circ} 21^{\prime} 09.24^{\prime \prime} \mathrm{E}$ & 263.536 \\
\hline
\end{tabular}




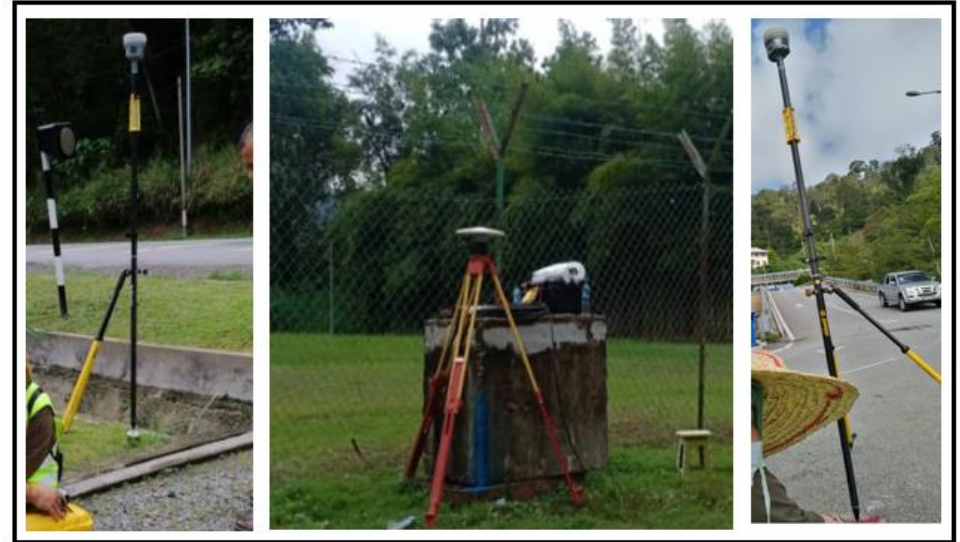

Figure 2: Base 1, Base 2 And Base 3 Which As The CORS Malaysia Reference Station.

\section{Module Description}

\section{GNSS}

To achieve the desired sub-cm accuracy, the location of the GNSS receiver must be positioned towards full-sky visibility to minimize major problems in GNSS surveillance such as multipath errors, troposphere delays, and limited visibility to satellites. Thus, the accurate positioning of the reference station at the GNSS data acquisition location makes it possible to obtain millimetre level position information on a short baseline $(<10 \mathrm{~km})$ (Bazanowski, SzostakChrzanowski, \& Chrzanowski, 2019).

The use of GNSS techniques is widespread as it requires only minimal interaction and cost savings. The device used to conduct this observation is the Trimble R10, and this device can detect signals from various satellite sources namely GPS, GLONASS, Galileo, QZSS and Beidou. The observation technique used 4 VRS for each reference station and the maximum distance between reference stations were around $30 \mathrm{~km}$ to $60 \mathrm{~km}$. During the observations, the PDOP was less than 5.0 with more than 12 satellites. The maximum epoch is 15 seconds and the satellite opening angle is about 10 degrees with the misclose baseline observations are $10 \mathrm{ppm}$.

\section{Accelerometer}

Abnormal movement detection is facilitated using an analogue accelerometer, which sensors on the various output of the voltage with a direct correlation to the magnitude of acceleration in each direction. Since a change in acceleration is inherent to movement, the accelerometer provides information that is subjected to the movements (Burchfield \& Venkatesan, 2007). The Accelerometer is useful for sensing vibrations in systems as well as for orientation applications. The accelerometer generates an analogue voltage for each axis that is relative to the acceleration force (in $\mathrm{g}$ units) parallel to that axis. The selected accelerometer has an adjustable sensitivity range that allows for fine-grained data acquisition at low $\mathrm{g}$ levels or a more coarsegrained data acquisition at higher $\mathrm{g}$ levels. The recorded and save the resultant accelerationtime history data from vibration caused by vehicles passing through the bridge, available from the data logger Dewesoft connected to the accelerometer. (Fernando et al., 2020). 


\section{Vibration Measurement At The Field}

The passing of the vehicles on the bridge induced vibration in the bridge due to the dynamic nature of the load applied. A wired accelerometer setup due to the performance of the vibration measurements of the bridge was during regular service conditions.

The accelerometer switched on at the same time as GNSS observation and wait for the vehicles to enter the bridge during the time set and finish. A smartphone stopwatch being used to determine the time measurements required to synchronize with the GNSS fast static mode and turned off the accelerometer.

To reduce significant or excessive vibration, research in the applicability of vibration is increasingly becoming the focus as well as practice in structural engineering where the work done is to assess the level of vibration of bridges, state by (Dong et al., 2020). Vibration can be the oscillations or repetitive motions of an object around an equilibrium position, where the force acting on it is zero. Vibration usually occurs because of the dynamic effects of manufacturing tolerances, clearances, rolling and rubbing contact between machine parts and out-of-balance forces in rotating and reciprocating members. They often time originate from small insignificant vibration and noise sources. Therefore, the practice of monitoring vibration is so important. The vibration body describes an oscillating motion as a reference position. The number of times a complete motion cycle takes place during one second is called the frequency and is measured in hertz $(\mathrm{Hz})$.

To acquire real traffic-induced vibration data, we deployed one Accelerometer (Shear Accelerometer Model \# 393B05, Serial \# 33008, Sensitivity; $10.36 \mathrm{~V} / \mathrm{g}\left(1.056 \mathrm{~V} / \mathrm{m} / \mathrm{s}^{2}\right)$ and the Bias level is at 11.6. Data acquisition happened in parallel using the vibration sensor and is connected to Sirius Mini 4 Channel of DEWEsoft Software for data processing and graphical production. Most civil structures are below $10 \mathrm{~Hz}$ as fundamental frequencies (Kim et al., 2007) and followed by the capacity of the Accelerometer is up to $160 \mathrm{~dB}$ to capture sound. Table 2 seen below is issued by Annex A Schedule of Recommended Vibration Limits Schedule 1 Recommended Limits for Damage Risk in Buildings from Steady State Vibration. This table revealed the characteristics of Damage Description on Vertical Vibration Peak Velocity, where this table can be related to the rating scale of manual inspection used by PWD officers when inspecting bridge structures. 


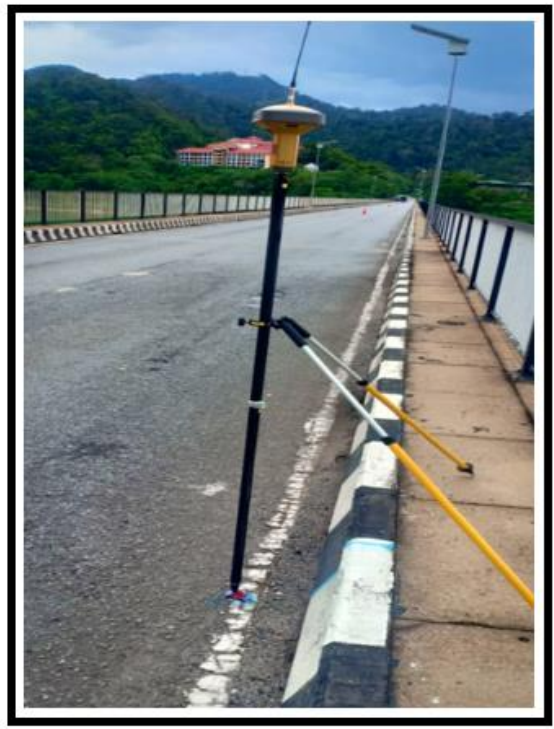

Figure 3: Position Of Observation Point At The Sg. Perak Reservoir Bridge.

Table 2: Annex A Schedule of Recommended Vibration Limits Schedule 1 Recommended Limits for Damage Risk in Buildings From Steady-State Vibration

\begin{tabular}{|c|c|}
\hline Damage Description & $\begin{array}{c}\text { Vertical Vibration Peak Velocity }(\mathbf{m a x}) \\
{\left[\mathbf{m m} / \mathbf{s}^{2}\right](\mathbf{0} \text { to Peak })(\mathbf{1 0}-\mathbf{1 0 0} \mathbf{H z})}\end{array}$ \\
\hline $\begin{array}{c}\text { Safe } \\
\text { Caution Level }\end{array}$ & 3 to 5 \\
(Damage Not Necessarily Inevitable $)$ \\
$\begin{array}{c}\text { Minor Damage } \\
\text { Major Damage }\end{array}$ & 5 to 30 \\
More Than 30
\end{tabular}

Source: (The Planning Guidelines For Vibration Limits And Control, 2004).

The natural frequencies of individual elements of the bridge were unknown in advance and likely to have higher vibration modes (Gaglione et al., 2018). Therefore, a sampling rate of $20,000 \mathrm{~Hz}$ was set at the Accelerometer. The data is locally stored at the device and downloaded in bulk at the end of the data acquisition period. The locations were chosen by trial and error aiming to find structural members showing high amplitude vibrations in the time domain of the frequency domain. The best locations seemed to be at the top of the pier members on the bridge slab, as shown in Figure 3.

\section{Results and Discussion}

Based on the findings of the Accelerometer readings in Table 3, the three samples of observation points at the pier showed that the readings at their respective locations were different according to the time of observation. The time allotted was throughout the day, as the location for observations was very limited and too dangerous. The data obtained should be performed simultaneously between the GNSS and the observation readings on the Accelerometer. The three observation points selected to be shown in this paper are at two points on the pier near the abutment and one in the middle of the bridge.

The three readings observed in the table are different and in line with the time of day. At eight o'clock in the morning, the vibration at the observation points with its coordinate readings was 
recorded to be in a minor state of $14.6 \mathrm{~mm} / \mathrm{s}^{2}$. These readings indicated that in the morning, the use of the bridge by heavy vehicles and cars was relatively less. The state of the vibration reading increases when at 11:00 am onwards and the location of the point observations are at coordinates Latitude: $4.598300006^{\circ}$, Longitude: $101.07903^{\circ}$. The highest reading for vibration at that point was $53.7 \mathrm{~mm} / \mathrm{s}^{2}$ with a major damage category. This indirectly indicated the traffic route is briskly increasing especially with the frequent use of heavy vehicles. The increase in the number of vehicles and the vibration readings not only affected the structure of the bridge, especially the pier, but the researchers and friends were able to also personally experience the vibrations themselves. The situation at that time was indeed very dangerous.

Next, when it was 14:20, the vibration at the observation points at the bridge abutment still higher and the reading was $49.6 \mathrm{~mm} / \mathrm{s}^{2}$, which is in the category of major damage. The bridge remained standing, looking strong and sturdy with its simple structure despite its condition of handling the frequency of heavy vehicles and cars passing through the bridge. This means that if the vibration conditions remained continuous with readings as high as more than $30 \mathrm{~mm} / \mathrm{s}^{2}$ without stopping, it is likely that the pier will more be damaged or there will be deformation on the pier of the bridge.

Observation procedures using GNSS can be the basis for use as a system, together with the use of other technical equipment. Data acquisition of GNSS from observation points can confirm the structure and assessment of the building conditions as it shows relatively small-time changes. Thus, the traffic load can be detected as a natural frequency change.

Table 3: Vibration Reading Value At The Observed Position.

\begin{tabular}{|c|c|c|c|}
\hline $\begin{array}{l}\text { Observation } \\
\text { Time }\end{array}$ & $\begin{array}{l}\text { Point of } \\
\text { pier }\end{array}$ & Coordinate & $\begin{array}{l}\text { Highest of Vibration } \mathrm{m} / \mathrm{s}^{2} \text { each } \\
\text { pier from Accelerometer }\end{array}$ \\
\hline $08: 00-08: 15$ & KB1 & $\begin{array}{c}X=759244.583 \\
Y=613356.53 \\
Z=252.795(h \text { in }(m))\end{array}$ & $\begin{array}{c}0.0146 \mathrm{~m} / \mathrm{s}^{2} \\
\left(14.6 \mathrm{~mm} / \mathrm{s}^{2}\right)-\text { minor }\end{array}$ \\
\hline $11: 20-11: 35$ & KB11 & $\begin{array}{c}X=758825.416 \\
Y=613327.240 \\
\mathrm{Z}=252.691(\mathrm{~h} \text { in }(\mathrm{m}))\end{array}$ & $\begin{array}{c}0.0537 \mathrm{~m} / \mathrm{s}^{2} \\
\left(53.7 \mathrm{~mm} / \mathrm{s}^{2}\right)-\text { major }\end{array}$ \\
\hline $14: 20-14: 35$ & KB20 & $\begin{array}{c}X=758418.763 \\
Y=613298.637 \\
Z=252.738(h \text { in }(m))\end{array}$ & $\begin{array}{c}0.0496 \mathrm{~m} / \mathrm{s}^{2} \\
\left(49.6 \mathrm{~mm} / \mathrm{s}^{2}\right)-\text { major }\end{array}$ \\
\hline
\end{tabular}

It is reasonable to assume that changes in stiffness can also be detected. If the structure deteriorates over of years under the action of normal loads or because of certain accidents that should occur, then this can be identified using GNSS because the reference satellite will be able to provide stable data (Roberts et al., 2012). GNSS has proven to be a good tool in measuring global deformation and will be a viable tool for assessing and determining the location of potential damage. However, a plan is needed in determining how many GNSS sensors are needed and where the sensors should be placed to obtain data at the locations studied (Meng, Roberts, Dodson, Ince, \& Waugh, 2006). 


\section{Graphical Representation}

The findings obtained from the use of the Accelerometer are shown in Figures 4, 5 and 6 as readings that were shown directly on the laptop display through the processing of observation data using DEWEsoft. The value displayed is the value obtained from the highest reading.

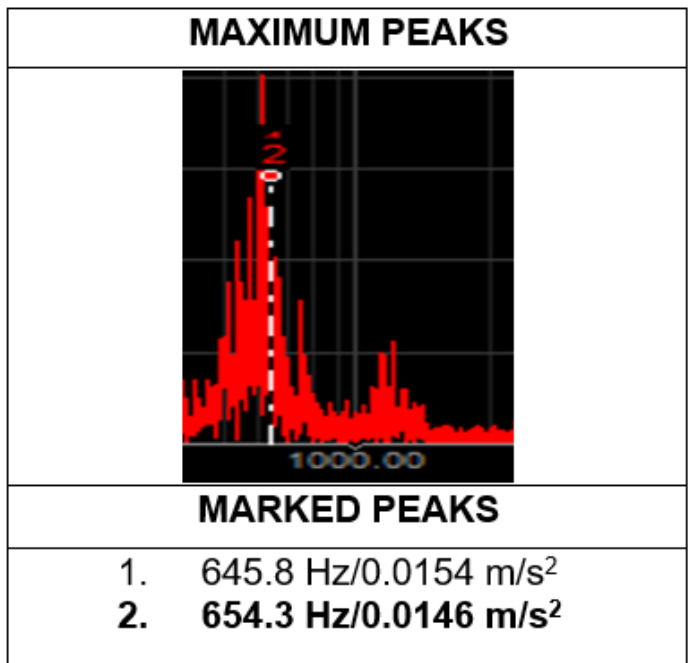

Figure 4: Output Of The Signal Of KB01 Observation Point.

By referring to Figure 4, the Reading obtained for the KB01 observation point, showed the values are at their maximum high peak when the observations were recorded. This data is directly displayed by the processing software and at that time, the list of numbers indicates the readings at its máximum. The reading on marked peaks of KB01 refers to the highest signal reading with a value of $0.0146 \mathrm{~m} / \mathrm{s} 2$.

The value choice for marked peaks vibration is obtained by observing the highest signal that is marked by a number displayed by the DEWESoft software interface.

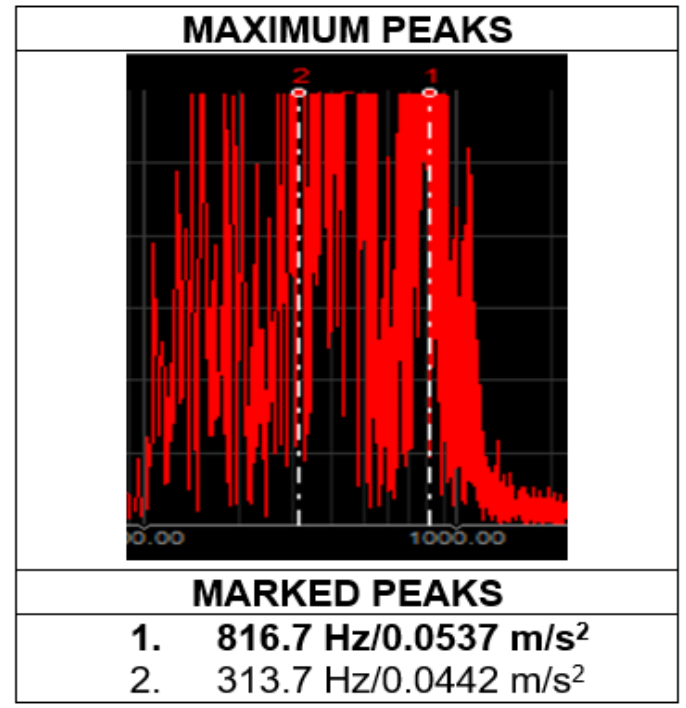

Figure 5: Output Of The Signal Of KB11 Observation Point. 


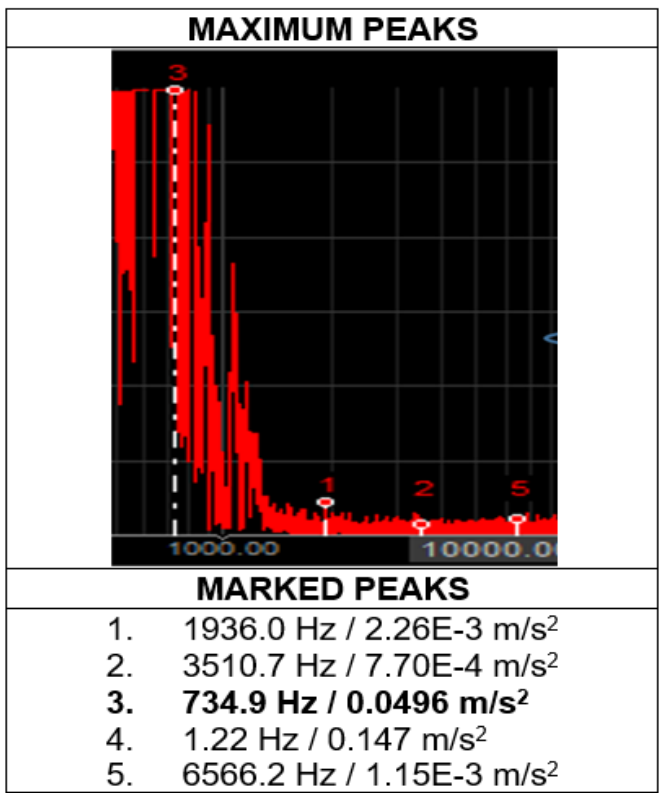

Figure 6: Output Of The Signal Of KB20 Observation Point.

For Figure 5 and Figure 6, each of them showed readings at the level of more than $30 \mathrm{~mm} / \mathrm{s}$, whereas the graphic with its signal displayed that showed its peak mark is chosen. All these 3 observation points were placed at the same point at the point position for the GNSS observation.

\section{Conclusion and Outlook}

Several causes can bring about damages or deterioration and produce changes in the structural vibration response such as vibration frequency damping ratio and mode shape. The basis behind this approach is that the vibration response depends on the structure of the bridge. The vibration reading value on a pier of point observation using the Accelerometer gave the highest vibration value reading in the required time. Even if too many values are recorded during data acquisition, the Dewesoft software will display the 5 highest vibration readings. Therefore, only one highest reading is taken and included in the table instead of the highest average reading. If the road surface i.e., the slab is in good and flat condition, certainly, the vibration will be even, and thus, the damage will also be minimal.

Based on this limited study, the analysis of the results leads to the following findings:

1. The sensitivity of GNSS signals is very high, providing the coordinate for each pier which can serve as very useful information to the inspectors.

2. Damage that is caused by vibration will increase due to the impact of heavy vehicles traffic movements.

Many existing bridges, which after several years of service are currently in need of intervention such as strengthening because the condition of concrete bridge assets is degrading due to ageing as they approach the end of their design life. (Gkoumas et al., 2021). 


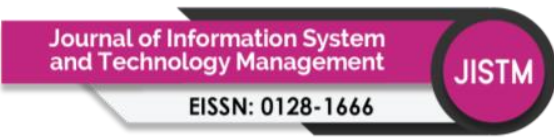

Volume 6 Issue 24 (December 2021) PP. 265-277

DOI: 10.35631/JISTM.624025

These observations if they are adhered to had indicated that there is a need for a very organized system or approach that is put in place to assist Public Works Department officers to regulate inspections regularly with assisted usage of GNSS and Accelerometer readings on any bridge structures.

\section{Acknowledgement}

The authors would like to express our gratitude and thanks to the data acquisition team, especially En. Adi Salihi Bin Adnan and Pn. Norfaiza Binti Mukaram Abid, from PWD. This research financially supported by the Ministry of Higher Education, Jabatan Pengajian Politeknik dan Kolej Komuniti (JPPKK) who has been directly involved in giving their permission and support to this research. This research work is part of Politeknik Ungku Omar Research Grant (No. P63 050110010001).

\section{References}

Aasim, B. A., Sor, M., \& Abdul, G. (2020). Vibration-based comparison of accelerometer and microtremor sensors with numerical verification by assessing a PC bridge. MIDAS Civil, 25-28.

Bao, T., \& Liu, Z. (2017). Vibration-based bridge scour detection: A review. Structural Control and Health Monitoring, 24(7). https://doi.org/10.1002/stc.1937

Bazanowski, M., Szostak-Chrzanowski, A., \& Chrzanowski, A. (2019). Determination of GPS session duration in ground deformation surveys in mining areas. Sustainability (Switzerland), 11(21). https://doi.org/10.3390/su11216127

Burchfield, T. R., \& Venkatesan, S. (2007). Accelerometer-based human abnormal movement detection in wireless sensor networks. Proceedings of the 1st ACM SIGMOBILE International Workshop on Systems and Networking Support for Healthcare and Assisted Living Environments, 67-69. https://doi.org/10.1145/1248054.1248073.

Chen, Z. Q., Zheng, S. X., Zhou, Q., Chen, Z. W., \& Li, X. (2020). Extreme value distribution and dynamic reliability estimation of high-pier bridges subjected to near-fault impulsive ground motions. Advances in Structural Engineering, 23(7), 1367-1382. https://doi.org/10.1177/1369433219894245

Dong, C. Z., Bas, S., \& Catbas, F. N. (2020). Investigation of vibration serviceability of a footbridge using computer vision-based methods. Engineering Structures, 224(October), 111224. https://doi.org/10.1016/j.engstruct.2020.111224

Fernando, K. S. D. M., Dissanayake, D. M. C. D., Dharmasiri, M. A. K. M., \& Dammika, A. J. (2020). Damage Detection and Condition Monitoring of Prestressed Concrete Bridges by using Vibrationbased Health Monitoring Techniques. Engineer: Journal of the Institution of Engineers, Sri Lanka, 53(3), 91. https://doi.org/10.4038/engineer.v53i3.7422

Gaglione, A., Rodenas-Herraiz, D., Jia, Y., Nawaz, S., Arroyo, E., Mascolo, C., ... Seshia, A. A. (2018). Energy Neutral Operation of Vibration Energy-Harvesting Sensor Networks for Bridge Applications. International Conference on Embedded Wireless Systems and Networks (EWSN), 1-12. Retrieved from https://ecc153fc-a-3b850097-ssites.googlegroups.com/a/ewsn.org/ewsn/file-repository/ewsn-

2018/001_012_gaglione.pdf?attachauth=ANoY7coy34cd6ViNLsRPJe2QuBZSuzSe8 eldlHx3W7BPO7vRLTV6WQjOV3NGcv7DVJ4FHw3XZ7OE8VlGjVyfNecK5HQaFQxv43uzXbg9Q4vj_FEM9GIEqz8bel OCiAt 
Gkoumas, K., Gkoktsi, K., Bono, F., Galassi, M. C., \& Tirelli, D. (2021). The way forward for indirect structural health monitoring (Ishm) using connected and automated vehicles in Europe. Infrastructures, 6(3). https://doi.org/10.3390/infrastructures6030043

Khodabandehlou, H., Pekcan, G., \& Fadali, M. S. (2019). Vibration-based structural condition assessment using convolution neural networks. Structural Control and Health Monitoring, 26(2), 1-12. https://doi.org/10.1002/stc.2308

Kim, S., Pakzad, S., Culler, D., Demmel, J., Fenves, G., Glaser, S., \& Turon, M. (2007). Health Monitoring of Civil Infrastructures Using Wireless Sensor Networks, 254-263. https://doi.org/10.1109/ipsn.2007.4379685

Meng, X., Roberts, G. W., Dodson, A. H., Ince, S., \& Waugh, S. (2006). GNSS for Structural Deformation and Deflection Monitoring: Implementation and Data Analysis. 3rd IAG Symposium on Geodesy for Geotechnical and Structural Engineering. 12th FIG Symposium on Deformation Measurement, (May).

Roberts, G. W., Brown, C. J., Meng, X., Ogundipe, O., Atkins, C., \& Colford, B. (2012). Deflection and frequency monitoring of the Forth Road Bridge, Scotland, by GPS. Proceedings of the Institution of Civil Engineers: Bridge Engineering, 165(2), 105-123. https://doi.org/10.1680/bren.9.00022.

The Planning Guidelines For Vibration Limits And Control, 2004. https://enviro2.doe.gov.my/ekmc/wp-content/uploads/2018/05/The-planningguidelines20180517_10110578.pdf

Xi, R., He, Q., \& Meng, X. (2021). Bridge monitoring using multi-GNSS observations with high cutoff elevations: A case study. Measurement: Journal of the International Measurement Confederation, 168(August), 108303. https://doi.org/10.1016/j.measurement.2020.108303 